\title{
Feasibility of the Transradial or the Transbrachial Approach in Various Neurointerventional Procedures
}

\author{
Dong Geun Lee, MD', ${ }^{\prime}$, Deok Hee Lee, MD, PhD', Jae Ho Shim, MD ${ }^{\prime, 3}$, Dae Chul Suh, MD, PhD'
}

Purpose: The generally preferred vascular access for neurointerventional procedures is the transfemoral approach (TFA). In complicated cases such as patients with aortic diseases or tortuous vessels, transradial or transbrachial approaches (TRA or TBA) could be good alternatives. The purpose of this study is to review a single medical center experience using the alternative accesses.

Materials and Methods: We reviewed the medical records of 30 TRA and 10 TBA cases among 2,073 cases treated between January 2010 and July 2013. We reviewed and analyzed the frequency of TRA and TBA, the reason the operator had chosen the TRA or TBA, the category of the procedure, caliber of the sheath, the success rate, and the complications rates.

Results: The most common reason the non-TFA route was chosen was due to the patient's tortuous vascular system $(n=24,60 \%)$. The most common category of intervention was balloon angioplasty and/or stent placement $(n=18,45 \%)$. The largest caliber of the introducing sheath was $6 \mathrm{Fr}$ in TRA and $7 \mathrm{Fr}$ in TBA. Procedural success was achieved in 37 cases (success rate: $92.5 \%$ ), and in three cases it failed. Six patients with complications were reported. Among them, four cases of minor complications $(10 \%)$ occurred. There was no serious complication directly related to the access problem.

Conclusion: Both TRA and TBA can be good alternative access routes when TFA is not appropriate in various neurointervential procedures.

Key Words : Therapeutic/methods; Endovascular technique; Transradial approach; Transbrachial approach; Transfemoral approach

\footnotetext{
'Department of Radiology, Research Institute of Radiology, Asan Medical Center, University of Ulsan College of Medicine, Seoul, Korea ${ }^{2}$ Department of Neurology, Sejong General Hospital, Bucheon, Korea

${ }^{3}$ Department of Radiology, Ulsan Hospital, Ulsan, Korea

Received March 12, 2015;

accepted after revision July 6, 2015.

Correspondence to: Deok Hee Lee, MD, PhD, Department of Radiology, Asan Medical Center, 88 Olympic-ro 43-gil, Songpa-gu, Seoul 138736, Korea.

Tel. 82.2.3010.5944 Fax. 82.2.476.0090

E-mail: dhlee@amc.seoul.kr

This is an Open Access article distributed under the terms of the Creative Commons Attribution Non-Commercial License (http://creativecommons.org/licenses/by-nc/3.0) which permits unrestricted non-commercial use, distribution, and reproduction in any medium, provided the original work is properly cited.
} 


\section{Dong Geun Lee, et al.}

The transfemoral approach (TFA) has been the standard route both for angiography and interventional procedures. However, we occasionally encountered situations in which the conventional TFA was not suitable for various reasons. In these situations, other routes such as the transradial approach (TRA) or the transbrachial approach (TBA) could be chosen.

In some medical centers, they prefer the TRA, especially for diagnostic angiography $[1,2]$. Because the TRA has been associated with a lower incidence of major access-site-related complications compared with the TFA $[3,4]$. A recent study showed an incidence of major access site vascular complications of $0.6 \%$ with the TRA versus $3.7 \%$ with the TFA [5]. As the radial artery is easily compressible, hemorrhagic complications are significantly reduced. Moreover, no major nerves or veins are located near the radial artery, thus minimizing the risk of injury to these structures. And post-procedural bed rest is not required, thus permitting immediate ambulation, more patient comfort, and early discharge, which may shorten the hospital stay and reduce healthcare costs $[6,7]$.

Despite its large number of benefits, the TRA requires a longer learning curve for the operator $[8,9]$. Moreover, it is not always feasible, as some patients may have an anomalous palmar arch that does not provide sufficient blood supply to the hand in cases of thrombotic, spastic or traumatic occlusion of the radial artery.

The purpose of this study is to review our clinical experience with the TRA and the TBA for various neurointerventional procedures.

\section{MATERIALS AND METHODS}

\section{Patient Population}

For various neurointerventional procedures performed in our institution, the primary vascular access site has been the femoral artery. Other alternative methods, such as the TRA or the TBA, have been adjunctive approaches for patients in whom the conventional TFA would have seemed difficult after reviewing the CT or MR angiographic findings or when prior diagnostic TFA angiography was difficult to perform. In that situation, the TRA has been the primary route. The TBA was chosen only when large-bore access was required. The right arm approach was done in every case except for the intentional left TRA used for the bidirectional approach to a left proximal subclavian artery occlusion [10].

After reviewing our neurointerventional database, we could extract 30 TRA and 10 TBA cases among 2073 neurovascular interventional cases treated between January 2010 and July 2013. This retrospective study was approved by our local institutional review board and the individual patient's consent was waived.

\section{Procedure}

Neurointerventional procedures were performed using biplane digital subtraction angiography suite (Axiom Artis, Siemens, Erlangen, Germany or Artis Zee, Siemens, Erlangen, Germany) in a supine patient position. Before the procedure, the Allen test was performed as previously described [11]. We counted the color returning time after releasing the ulnar artery compression. We considered the palmar arch collateral as insufficient when the returning time was longer than five seconds, and in that situation we did not perform the TRA. An alternative portal approach, such as the brachial or femoral artery, was then considered. The results of this test demonstrated adequate collateral blood flow in all 40 patients.

For the TRA, the patient's right arm was placed in a supine position with extension of the wrist over a dedicated arm rest. By palpation of the radial artery pulsation near the radial process, we could identify the strongest pulsating point where we could achieve local anesthesia infiltration by subcutaneous injection of a small aliquot (1-2 $\mathrm{ml}$ ) of $2 \%$ lidocaine, thus creating a small, cutaneous bulge. The radial artery was punctured using a 21-gauge micropuncture system (Cook, Bloomington, IN, USA) or a 20-gauge, Teflonsheathed needle (Terumo, Tokyo, Japan). A 5- or 6french $(\mathrm{Fr})$ vascular sheath (Terumo or Cook) was then introduced. To prevent vasospasm of the artery, a diluted solution of nitrate (nitroglycerine 150-250 microgram) and/or calcium-channel blocker (verapamil 150-250 mg) was injected intra-arterially through the sheath which was then continuously flushed with pressurized, heparinized saline during the procedure. A 5 Fr or 6 Fr guiding catheter was placed in the vessel of interest through the brachial-axillary-subclavian artery route.

For patients in whom the TRA was impossible or a larger-bore catheter was required, the TBA was done with the same arm positioning as that of the TRA. By palpating the maximal pulsating point above the elbow, we could identify the optimal puncture site of the brachial artery. For the initial puncture of the artery, a 21-gauge, micropuncture system or a 20 -gauge, Teflonsheathed needle was used. We could introduce up to a 7 Fr introducing sheath in cases of the TBA and a $6 \mathrm{Fr}$ in 


\section{Dong Geun Lee, et al.}

cases of the TRA. Most of the non-TFA, carotid revascularization procedures were done with the TBA as it required a larger-bore system for the delivery of the stent system.

After the introducing sheath was introduced, a guiding catheter over a $4 \mathrm{~F}$ or $5 \mathrm{~F}$ Simmons catheter (Cook or Jungsung Medical, Sungnam, Korea) was introduced over a hydrophilic guide wire (Terumo) using a coaxial technique. We primarily used Simmons type 2 catheters. Type 3 catheters were also useful for patients with a large body habitus. We could select the right vertebral artery with the guide wire directly. We could select between the right common carotid artery and the left verterbral artery, as previously described [1]. In cases of left subclavian stent insertion, we used the left TRA.

After completion of the procedure, we attempted local hemostasis simply by using a pressure bandage with four, elastic sticky straps with a subsequent 5-10min manual compression at the puncture site. Patients were not allowed to use the punctured arm for two hours after the procedure. The bandage was removed six hours after the procedure.

\section{Analysis}

We summarized the demographic data of the nonTFA patients. We reviewed the reason why the operator had chosen the TRA or the TBA rather than the conventional TFA together with the category of the procedure and the vessel of interest. Basic, procedure- related facts were also reviewed. Procedural success and its rate were analyzed. We regarded a procedure successful when all of the neurointerventional procedures were done as intended and without changing the access site. The caliber of the introducing sheath and the guiding catheter were recorded. The procedure duration, defined as the time interval from the arterial puncture to completion of the angiography, was also recorded. Procedural and local access-related complications and their rates were analyzed.

\section{RESULTS}

A total of 40 patients were included in our review. Among them, half were male. The age ranged from 20 to 81 years, with a median age of 67 years (IQR 60.870.3). Pre-procedural variables are summarized in Table 1. Thirty procedures were done with the TRA and 10 procedures with the TBA. Because of the need for the rendezvous approach [10], we simultaneously performed the TRA or the TBA with the TFA from the beginning of the procedure in four patients (2 TRA+TFA, 2 TBA+TFA).

The most common reason the operator chose the TRA or the TBA rather than the TFA was the tortuosity of the accessing arteries $(n=23,57.5 \%)$ (Fig. 1) as well as various other reasons (Table 1). In 11 cases, the TFA was tried first but switched to the TRA $(n=8)$ or the TBA $(n=3)$ because of the instability of the guiding catheter positioning or inappropriate support from the
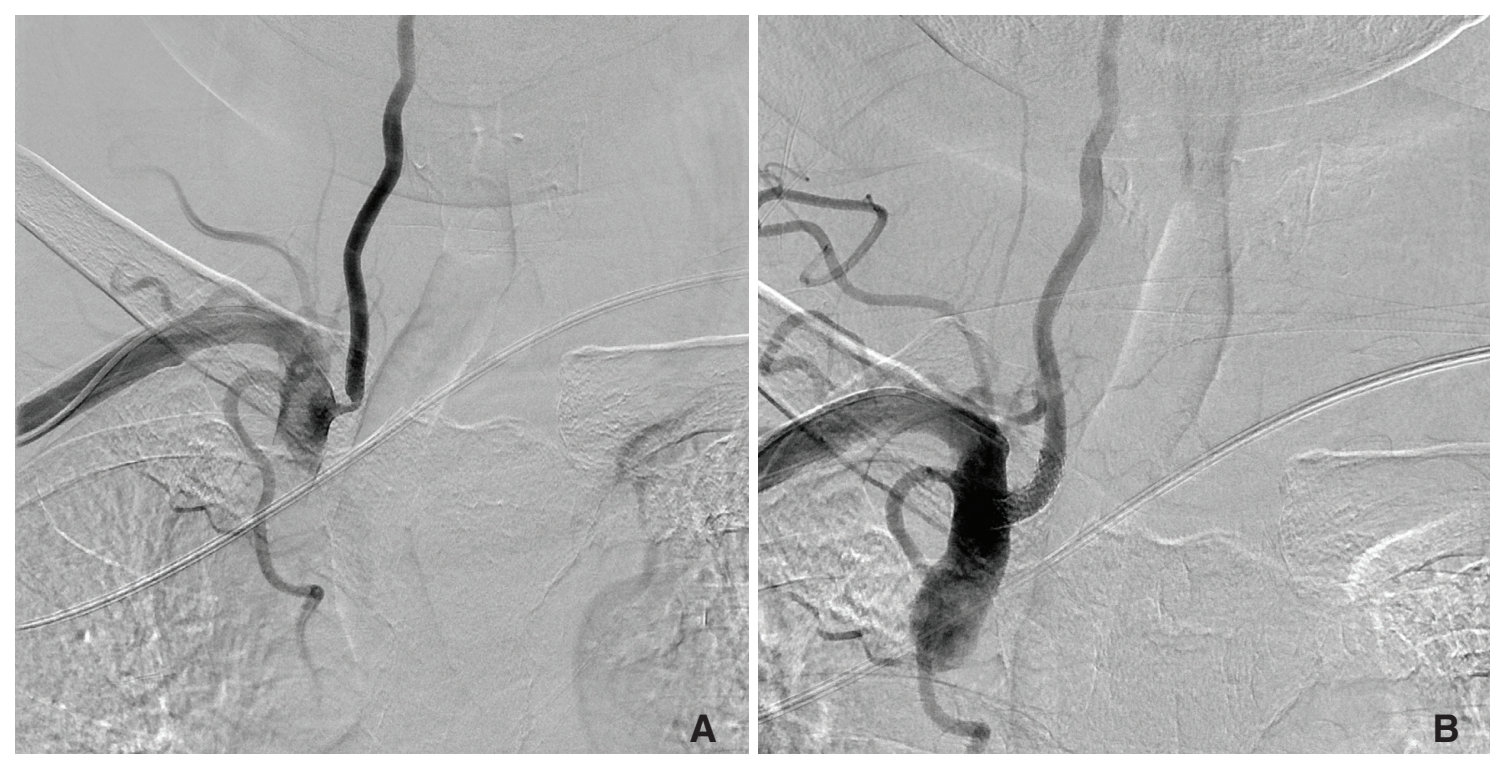

Fig. 1. A 73-year-old man with stenosis of the right, vertebral artery ostium.

A. The right, vertebral artery angiogram reveals severe stenosis of the right vertebral artery ostium.

B. Using a transradial approach, we could perform balloon angioplasty and stent deployment. It took 18 minutes from the puncture to the final angiography. 


\section{Dong Geun Lee, et al.}

guiding catheter due to the tortuous vascular system.

In two cases which were originally planned for a TRA procedure, we had no choice but to switch to the TBA because of the positive Allen test. There was no case in which we switched from the TRA or the TBA to the TFA.

The most common category of intervention was balloon angioplasty and/or stent placement $(n=18$, $45 \%$ ). Other categories of intervention are listed in Table 1. The most common vessel of interest was the basilar artery $(n=10,25 \%)$ followed by the right vertebral artery ( $\mathrm{n}=6,15 \%)$ (Fig. 2).

Procedural success was achieved in 37 cases (success rate: $92.5 \%$ ). Causes of failure were failure of microcatheter passage through the occluded target segment during the intracranial stenting procedure $(n=2)$ and failure of microcatheter delivery into the very tortuous cortical branch of the posterior cerebral artery during the mycotic aneurysm embolization procedure (Fig. 3). Details of the failed cases are described in Table 2.

In the TRA, the most frequently used caliber of the introducing sheath was $5 \mathrm{Fr}(\mathrm{n}=22,73 \%)$, and the largest caliber of the introducing sheath was 6 Fr. In the TBA, the most frequently used caliber of the introducing sheath was $6 \mathrm{Fr}(\mathrm{n}=4,40 \%)$, and the largest caliber of the introducing sheath was $7 \mathrm{Fr}$.
The median procedure time was 86 minutes (IQR 61$112 \mathrm{~min}$ ). The maximum procedure time was 226 minutes during the embolization of the thoracic

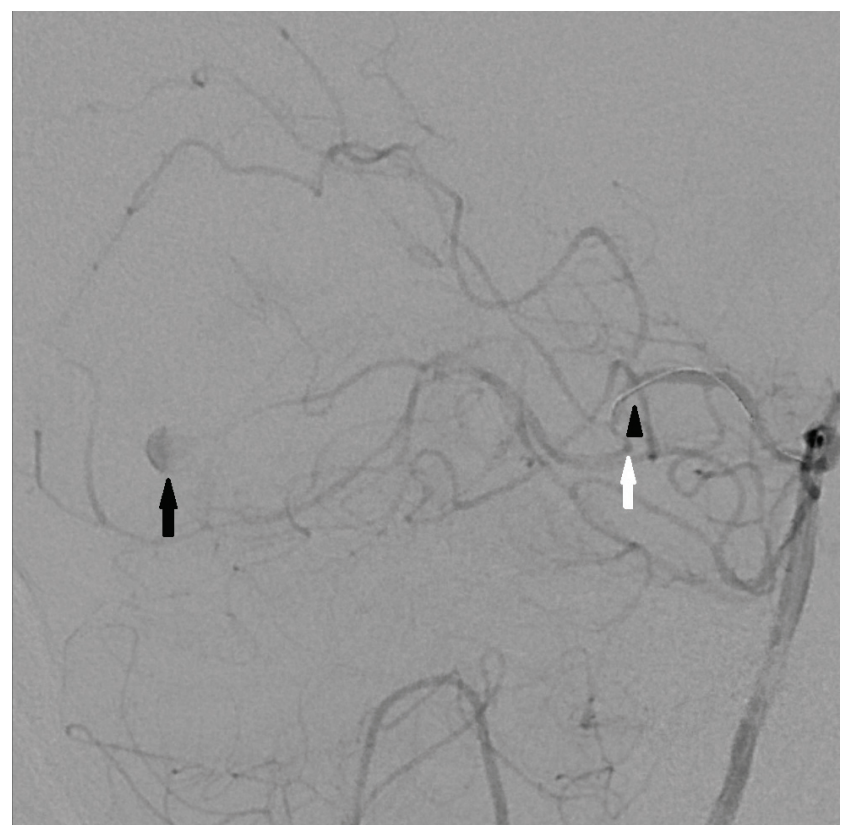

Fig. 3. A 62-year-old woman with a mycotic aneurysm of the right posterior cerebral artery. The microcatheter (arrow head) could not navigate into the mycotic aneurysm (black arrow) because of the very acute angulation (white arrow) of the posterior cerebral artery.

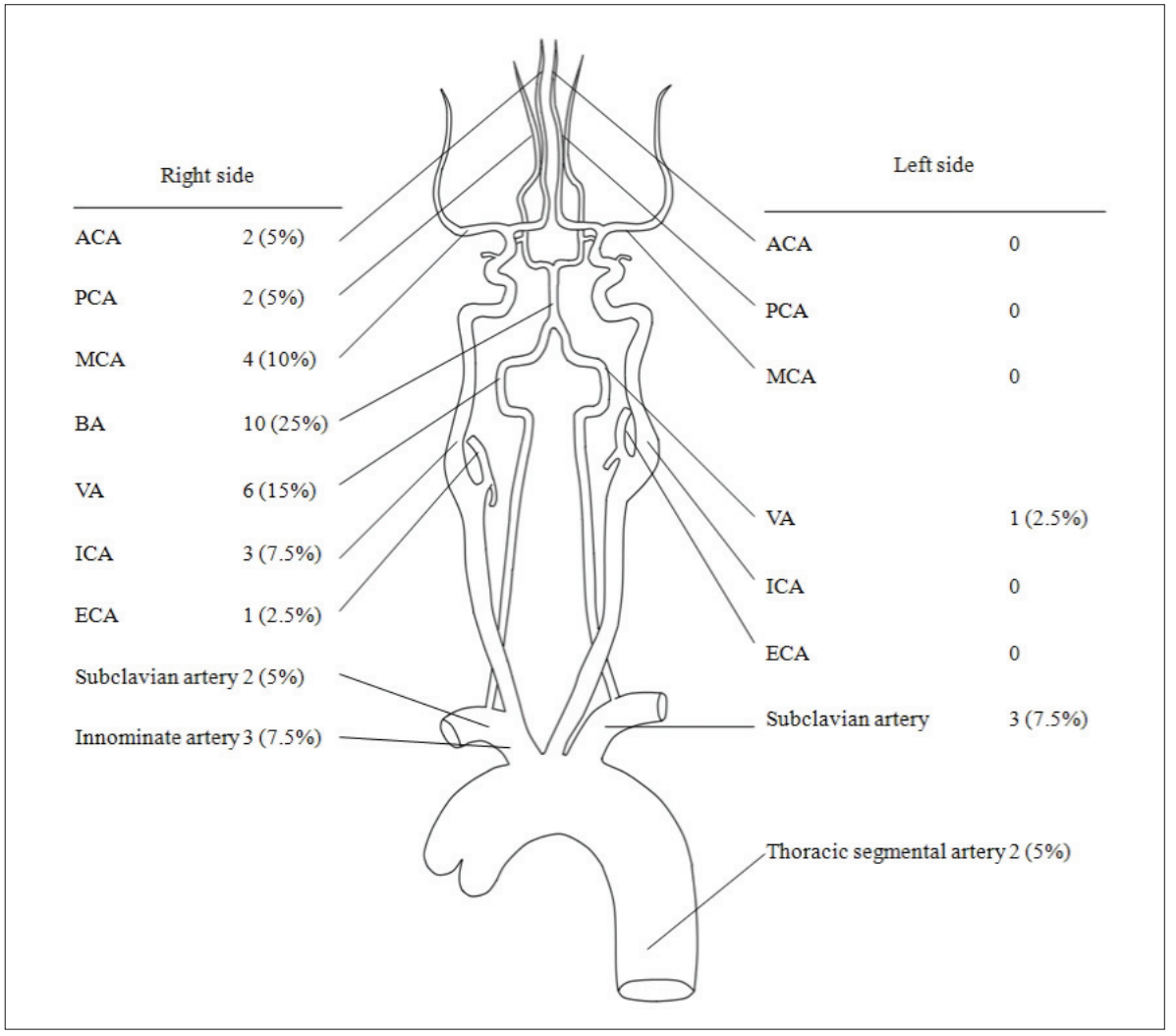

Fig. 2. Vessels of interest.

ACA, Anterior cerebral artery; PCA, posterior cerebral artery; MCA, middle cerebral artery; BA, basilar artery; VA, vertebral artery; ICA, internal cerebral artery; ECA, external cerebral artery 


\section{Dong Geun Lee, et al.}

vertebral body tumor. The minimum procedure time was 18 minutes during stent insertion in the right vertebral artery ostium stenosis (Fig. 4).

There were four cases of access-related complications. All of them were minor, i.e. puncture site pain in two TRA cases and puncture site hematoma in two TBA cases, and self-limited without any clinical sequelae. There was a case of procedure-related complication of thromboembolism and a case of mortality due to septic shock which was not directly related to the interventional procedure.

\section{DISCUSSION}

With this clinical experience, we believe that the TRA and the TBA are good alternative access routes for various neurointerventional procedures. We accomplished almost all kinds of interventional procedures with a high success rate except for cases of carotid stent insertion. We sent the patient for carotid endarterectomy when the usual TFA was not suitable. However, as there are several, low-profile devices available in the market, we could attempt carotid
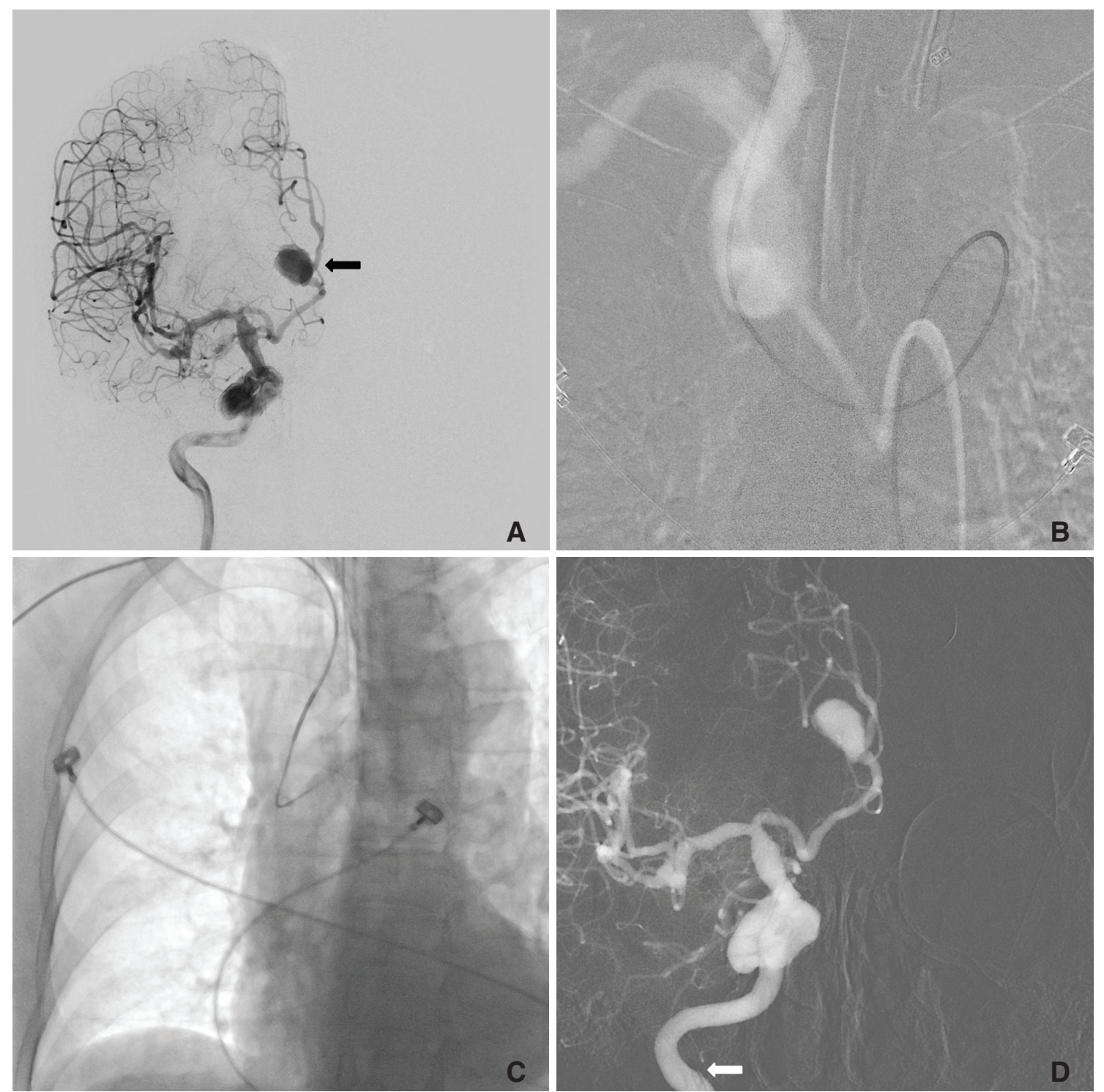

Fig. 4. A 74-year-old woman with an unruptured aneurysm of the right anterior cerebral artery

A. The right internal carotid angiogram reveals a 12-mm $\times 9-\mathrm{mm}$, saccular aneurysm (black arrow) arising from the A2 segment of the right anterior cerebral artery.

B. Using a transfemoral approach, we could not secure stable guiding because of the tortuous vascular system.

C, D. Using a transbrachial approach, we could easily select the right internal carotid artery with stable guiding support. The tip of the guiding catheter (white arrow) is located in the internal cerebral artery. 


\section{Dong Geun Lee, et al.}

stenting if a patient's condition was not suitable for the CEA procedure. Therefore, we believe that we can perform almost all neurointerventional procedures with these non-TFAs.

Given that in our series the most common reason for switching from the TFA to the TRA or the TBA was

Table 1. Pre-procedural data $(n=40)$

\begin{tabular}{|c|c|}
\hline Procedure route & \\
\hline TRA & $28(70 \%)$ \\
\hline TRA + TFA & $2(5 \%)$ \\
\hline TBA & $8(20 \%)$ \\
\hline TBA + TFA & $2(5 \%)$ \\
\hline \multicolumn{2}{|l|}{ Reason for non-TFA } \\
\hline Tortuous vascular system & $23(57.5 \%)$ \\
\hline Tight stenosis close to aortic arch & $4(10 \%)$ \\
\hline Need of rendezvous approach & $4(10 \%)$ \\
\hline Aortic dissection & $3(7.5 \%)$ \\
\hline Bilateral iliac occlusions & $3(7.5 \%)$ \\
\hline Operator's preference & $2(5 \%)$ \\
\hline Reversed ostial direction & $1(2.5 \%)$ \\
\hline \multicolumn{2}{|l|}{ Category of Intervention } \\
\hline Stent placement & $18(45 \%)$ \\
\hline Aneurysm embolization & $16(40 \%)$ \\
\hline Preoperative tumor embolization & $3(7.5 \%)$ \\
\hline Mechanical thrombectomy & $2(5 \%)$ \\
\hline dAVF embolization & $1(2.5 \%)$ \\
\hline
\end{tabular}

TRA, transradial approach; TFA, transfemoral approach; TBA, transbrachial approach; dAVF, dural arteriovenous fistulae the unstable guiding catheter support due to the tortuous vascular system ( 5 of $11,45 \%$ ), we could achieve stable guiding catheter support using our alternative approach. As the TRA or the TBA can bypass the tortuosity of the aorta and the iliac artery, and the way from the radial artery to the subclavian artery is of a narrow caliber and is straight, the TRA and the TBA can offer more stable support for the guiding catheter.

However, there could be several caveats regarding the TRA or the TBA. Due to the anatomic configuration of the right brachiocephalic trunk and the aortic arch, the approach into the left subclavian artery or left VA could be difficult. This was why the number of cases in these target vessels was small. Moreover, due to the smaller vessel diameter of the radial artery, the size of the introducer sheaths was smaller. We preferred 5 or $6 \mathrm{~F}$ for the TRA. When a larger-bore catheter was required, we preferred the TBA [13].

In all cases, we placed a short sheath in the artery and then placed guiding catheters through this sheath. We do not recommend the use of long sheaths in the radial artery system. In particular, the use of "guiding sheaths," where the sheath itself is advanced to the target territory as in transfemoral carotid stent placement, has not been done in our clinical practice. Authors have previously applied this technique with resultant radial artery occlusion [14]. Although with a small cases series, we have not experienced major complications of the radial artery, such as radial artery occlusion or rupture of the radial artery. Some reports propose that these major complications stem from the long and large diameter of the introducing catheter [14]. Therefore, avoiding a large and long catheter would prevent such major complications.

Table 2. Brief Summary of Failed Cases

\begin{tabular}{|c|c|c|c|c|c|c|c|c|c|}
\hline Sex & Age & $\begin{array}{l}\text { Indication of } \\
\text { intervention }\end{array}$ & Approach & Reason for TRA & Sheath & $\begin{array}{l}\text { Guiding } \\
\text { catheter }\end{array}$ & $\begin{array}{l}\text { Procedure } \\
\text { time (min.) }\end{array}$ & $\begin{array}{l}\text { Cause of } \\
\text { failure }\end{array}$ & Complication \\
\hline $\mathrm{F}$ & 62 & $\begin{array}{l}\text { Right PCA mycotic } \\
\text { aneurysm }\end{array}$ & TRA & $\begin{array}{l}\text { Tortuous vascular } \\
\text { system }\end{array}$ & $5 \mathrm{Fr}$ & $5 \mathrm{Fr}$ & 102 & $\begin{array}{l}\text { Too acute angulation } \\
\text { of the vessel for } \\
\text { microcatheter to pass }\end{array}$ & No \\
\hline $\mathrm{M}$ & 49 & $\begin{array}{l}\text { Right VB junction } \\
\text { occlusion }\end{array}$ & TRA & $\begin{array}{l}\text { Tortuous vascular } \\
\text { system }\end{array}$ & $5 \mathrm{Fr}$ & $5 \mathrm{Fr}$ & 33 & $\begin{array}{l}\text { Failure of guidewire } \\
\text { passage due to } \\
\text { organized occlusion }\end{array}$ & No \\
\hline $\mathrm{M}$ & 74 & $\begin{array}{l}\text { Innominate artery } \\
\text { occlusion }\end{array}$ & TRA & $\begin{array}{l}\text { Tight stenosis very } \\
\text { close to aortic arch }\end{array}$ & $5 \mathrm{Fr}$ & $4 \mathrm{Fr}$ & 46 & $\begin{array}{l}\text { Failure of guidewire } \\
\text { passage due to } \\
\text { organized occlusion }\end{array}$ & No \\
\hline
\end{tabular}

TRA, transradial approach; TFA, transfemoral approach; TBA, transbrachial approach 


\section{Dong Geun Lee, et al.}

Concern remains regarding the risk of permanent injury to the radial artery, especially with the use of larger sheaths. There is a vast number of literature reports regarding the risks of radial artery access procedures for coronary indications. These reports have shown the risk of permanent radial artery injury to be low, even after multiple procedures in the same radial artery [15]. If careful documentation of patency of the palmar arch is performed, then the risk of injury to the hand is minimal, even if the radial artery is permanently damaged.

Another issue we must discuss is that of delayed granuloma formation of the puncture site [16]. Hydrophilic coating of the sheath is helpful for spasm of the radial artery [17], however, stripped hydrophilic materials could be the source of aseptic inflammation of the puncture site [16]. Although we did not have such a case, we should aware of the possibility.

The transradial approach has a steep and significant learning curve, increased X-ray exposure time, difficulty in catheterizing the branch vessels, increased pain during the procedure, radial artery spasm, and limitation of continued access in the same arm [18]. Jo et al. [19] reported $5.2 \%$ failure of radial artery puncture. The small caliber $(2-3.5 \mathrm{~mm}$ in diameter) and the alpha? adrenergic innervations of the artery make the puncture task the key point of a successful transradial procedure. When the accurate site of puncture has been correctly identified, the most critical step of the radial catheterization procedure begins. Different puncture techniques exist, although currently the most commonly used by experienced radial operators is the over-the-needle technique. As described in many published studies, the TRA [20] puncture remains, for beginners, the cornerstone of the learning curve, and it takes time to develop all the skills required, even for clinically experienced interventional neuroradiologists. Obtaining arterial access by a single or a limited number of puncture attempts is probably the best way to avoid difficulties linked to a refractory spasm following a difficult puncture (20).

Although we listed the cons for the TRA and the TBA, these approaches have additional merits compensating for these problems. First, easy hemostasis is the single most important advantage. It is not necessary to compress the puncture site manually, as a simple compression bandage is sufficient for hemostasis, with few cases of puncture-site hematoma formation in our series, compared with a groin hematoma formation rate with transfemoral access reported to be as high as $10 \%$ [21]. Transradial access allows the patient to be ambulatory immediately after the procedure. This allows cerebral angiography to be easily performed on an out-patient basis and useful for the imaging followup of patients after carotid or vertebral artery stenting.

Second, there is no need to stop antiplatelet or anticoagulation treatment in patients at risk for atherosclerotic or cardioembolic disease. It may be difficult and time-consuming to readjust the level of anticoagulation after angiography if this has been stopped for the angiogram.

Third, in some complicated cases, such as aortic diseases, tortuous vascular structure, and anatomical variations, these obstacles could be easily bypassed using the TRA or TFA, providing stable guiding support, especially when the lesion is located in the right side. Fourth, it is possible that the wrist and forearm may be a more patient-friendly route than the conventional TFA.

Our study has some limitations. First, our number of cases is small, the technical success rate might be overestimated, and the potential adverse events might be underestimated. Second, this study just reviewed our clinical experience with the TRA and the TBA. So we could not compare the clinical aspects of the TRA or TBA to the TFA directly.

\section{CONCLUSION}

The radial artery and brachial artery are fulfilling alternatives to femoral artery access in neurointerventional procedures, and it is especially useful when the target lesion is located on the right side. Interventional neuroradiologists should become familiar with radial and brachial artery access in order to provide comprehensive endovascular care to their patients.

\section{References}

1. Lee DH, Ahn JH, Jeong SS, Eo KS, Park MS. Routine transradial access for conventional cerebral angiography: a single operator's experience of its feasibility and safety. Br J Radiol 2004;77:831838

2. Kim JH, Park YS, Chung CG, Park KS, Chung DJ, Kim HJ. Feasibility and utility of transradial cerebral angiography: experience during the learning period. Korean J Radiol 2006;7:7-13

3. Agostoni P, Biondi-Zoccai GG, de Benedictis ML, Rigattieri S, Turri M, Anselmi M, et al. Radial versus femoral approach for percutaneous coronary diagnostic and interventional procedures: Systematic overview and meta-analysis of randomized trials. $J \mathrm{Am}$ Coll Cardiol 2004;44:349-356

4. Jolly SS, Yusuf S, Cairns J, Niemela K, Xavier D, Widimsky P, et al. Radial versus femoral access for coronary angiography and intervention in patients with acute coronary syndromes (RIVAL): 


\section{Dong Geun Lee, et al.}

a randomised, parallel group, multicentre trial. Lancet 2011;377:1409-1420

5. Brueck M, Bandorski D, Kramer W, Wieczorek M, Holtgen R, Tillmanns H. A randomized comparison of transradial versus transfemoral approach for coronary angiography and angioplasty. JACC Cardiovasc Interv 2009;2:1047-1054

6. Cooper CJ, El-Shiekh RA, Cohen DJ, Blaesing L, Burket MW, Basu A, et al. Effect of transradial access on quality of life and cost of cardiac catheterization: A randomized comparison. Am Heart J 1999;138(3 Pt 1):430-436

7. Mann JT, 3rd, Cubeddu MG, Schneider JE, Arrowood M. Right Radial Access for PTCA: A Prospective Study Demonstrates Reduced Complications and Hospital Charges. J Invasive Cardiol 1996;8 Suppl D:40D-4D

8. Louvard Y, Pezzano M, Scheers L, Koukoui F, Marien C, Benaim $\mathrm{R}$, et al. Coronary angiography by a radial artery approach: feasibility, learning curve. One operator's experience. Arch Mal Coeur Vaiss 1998;91:209-215

9. Goldberg SL, Renslo R, Sinow R, French WJ. Learning curve in the use of the radial artery as vascular access in the performance of percutaneous transluminal coronary angioplasty. Cathet Diagn 1998;44:147-152

10. Park S, Kwak JH, Baek HJ, Park JW, Kim JS, Suh DC. The Use of Protection Device in Landmark-wire Technique of Symptomatic Subclavian Artery Occlusion with Combined Approach via Trans-femoral vs. Trans-brachial Arteries: Technical note. Neurointervention 2011;6:89-94

11. Allen E. Thromboangiitis obliterans: methods of diagnosis of chronic occlusive arterial lesions distal to the wrist with illustrative cases. Am J Med Sci 1929;178:8

12. Gunasekaran S, Kallarakkal JT, Thanikachalam S. Percutaneous transluminal coronary angioplasty by right transradial approach in a patient with arteria lusoria. Indian Heart J 2006;58:365-367

13. Layton KF, Kallmes DF, Cloft HJ. The radial artery access site for interventional neuroradiology procedures. AJNR Am J Neuroradiol 2006;27:1151-1154

14. Levy EI, Kim SH, Bendok BR, Qureshi AI, Guterman LR, Hopkins LN. Transradial stenting of the cervical internal carotid artery: technical case report. Neurosurgery 2003;53:448-451

15. Saito S, Miyake S, Hosokawa G, Tanaka S, Kawamitsu K, Kaneda H, et al. Transradial coronary intervention in Japanese patients. Catheter Cardiovasc Interv 1999;46:37-41

16. De Leon D, Swank G, Mirza MA. Radial artery sterile granulomatous reaction secondary to hydrophilic-coated sheath used for transradial cardiac catheterization: a case series. Angiology 2012;63:560-562

17. Rathore S, Stables RH, Pauriah M, Hakeem A, Mills JD, Palmer $\mathrm{ND}$, et al. Impact of length and hydrophilic coating of the introducer sheath on radial artery spasm during transradial coronary intervention: a randomized study. JACC Cardiovasc Interv 2010;3:475-483

18. Sakai H, Ikeda S, Harada T, Yonashiro S, Ozumi K, Ohe H, et al. Limitations of successive transradial approach in the same arm: the Japanese experience. Catheterization and cardiovascular interventions : official journal of the Society for Cardiac Angiography \& Interventions 2001;54:204-208

19. Jo KW, Park SM, Kim SD, Kim SR, Baik MW, Kim YW. Is Transradial Cerebral Angiography Feasible and Safe? A Single Center's Experience. J Korean Neurosurg Soc 2010;47:332-337

20. Guedes A, Dangoisse V, Gabriel L, Jamart J, Chenu P, Marchandise B, et al. Low rate of conversion to transfemoral approach when attempting both radial arteries for coronary angiography and percutaneous coronary intervention: a study of 1,826 consecutive procedures. J Invasive Cardiol 2010;22:391397

21. Moran CJ, Milburn JM, Cross DT, 3rd, Derdeyn CP, Dobbie TK, Littenberg B. Randomized controlled trial of sheaths in diagnostic neuroangiography. Radiology 2001;218:183-187 